CLINICAL STUDY

\title{
Transient hyper-17-hydroxyprogesteronemia: a clinical subgroup of patients diagnosed at neonatal screening for congenital adrenal hyperplasia
}

\author{
Paolo Cavarzere ${ }^{1,2}$, Dinane Samara-Boustani ${ }^{1}$, Isabelle Flechtner ${ }^{1}$, Michèle Dechaux ${ }^{3}$, Caroline Elie ${ }^{4}$, \\ Véronique Tardy ${ }^{5}$, Yves Morel ${ }^{5}$ and Michel Polak ${ }^{1}$ \\ ${ }^{1}$ Pediatric Endocrinology Unit, INSERM U845, Hôpital Necker-Enfants Malades, Paris Descartes University, 75748 Paris, France, ${ }^{2}$ Department of \\ Pediatrics, University of Verona, Polyclinic G.B. Rossi, Piazzale Scuro 10, 37134 Verona, Italy, ${ }^{3}$ Service d'Explorations Fonctionnelles, Paris Descartes \\ University, Paris, France, ${ }^{4}$ Service de Biostatistique, Hôpital Necker-Enfants Malades, Paris, France and ${ }^{5}$ Biochimie Endocrinienne et Moléculaire, Hôpital \\ Debrousse, INSERM U329, Lyon, France
}

(Correspondence should be addressed to P Cavarzere at Department of Pediatrics, University of Verona; Email: paolocavarzere@yahoo.it)

\begin{abstract}
Objective: Neonatal screening for congenital adrenal hyperplasia $(\mathrm{CAH})$ is characterized by a high false-positive rate, mainly among preterm and low birth weight infants. The aims of this study were to describe a subgroup of infants with transient serum hyper-17-hydroxyprogesteronemia (hyper-17-OHPemia) and to compare them with false positive and affected by 21-hydroxylase deficiency newborns.

Methods: We retrospectively analyzed the clinical data of all newborns positive at CAH neonatal screening, who were referred to our hospital to confirm the diagnosis from 2002 to 2006. They were submitted to clinical investigations and blood tests to evaluate 17-hydroxyprogesterone (17-OHP), renin, and electrolyte levels. CAH-unaffected newborns with increased serum 17-OHP were submitted to strict follow-up monitoring, which included an ACTH-stimulating test and genetic analysis of the 21-hydroxylase gene, until serum 17-OHP decreased.

Results: Thirty-seven newborns with gestational ages ranging from 33 to 40 weeks were studied. Eight infants (three male and five female) were affected by CAH (serum 17-OHP: 277.5 (210-921) $\mathrm{nmol} / \mathrm{l}), 14$ (ten male and four female) were false positives (17-OHP: $3.75(0.3-8.4) \mathrm{nmol} / \mathrm{l})$, and 15 (ten male and five female) showed a serum hyper-17-OHPemia (17-OHP: 15.9 (9.9-33) nmol/l). No mutations of the 21-hydroxylase gene were found in infants with hyper-17-OHPemia and their serum 17-OHP levels were normalized by the third month of life.

Conclusion: We identified a population of infants with transient serum hyper-17-OHPemia, and no clinical signs of disease or 21-hydroxylase gene mutations. No further investigations are necessary after birth in these newborns if 17-OHP levels decrease, other confirmatory tests such as ACTH-stimulation test or genotyping analysis are necessary only if symptoms appear.
\end{abstract}

European Journal of Endocrinology $161285-292$

\section{Introduction}

Congenital adrenal hyperplasia (CAH) is an autosomal recessive disorder due to a deficiency in one of the five enzymes necessary for the adrenal biosynthesis of cortisol from cholesterol $(1,2)$. The most frequent form of CAH, accounting for $~ 90-95 \%$ of all cases, is due to 21-hydroxylase deficiency (21-OHD) (3, 4). Clinically, 21-OHD displays heterogeneous features ranging from a classic form caused by the total absence of enzymatic function and consisting in the salt wasting or the less common simple virilizing type, to the nonclassical form, asymptomatic or characterized by different hyperandrogenic signs that may manifest from childhood to adulthood (5-7).

A neonatal screening program for 21-OHD based on 17-hydroxyprogesterone (17-OHP) assay on the filter paper-dried blood spots was initiated in order to avoid potential early life-threatening shock and death, especially in male newborns, and incorrect sex assignment in affected girls with inappropriate virilization (8-11). In France, a national program for massive $\mathrm{CAH}$ neonatal screening was started in 1995 after an initial pilot study (12).

A significant drawback of neonatal screening for 21-OHD is the high false-positive rate, mainly among ill, preterm, and low birth weight (BW) infants (13-15). Therefore, the different screening programs have established 17-OHP cut-off levels in relation to gestational age (GA) $(13,16-20)$ or $\mathrm{BW}(21,22)$, so that the falsepositive rate could be reduced.

Once a blood-spot value exceeding the threshold level has been discovered, a full clinical and biochemical evaluation is imperative to confirm the screening 
suspicion (23). Affected girls may show ambiguous external genitalia, whereas males are often asymptomatic; both present high serum levels of 17-OHP and, to a lesser extent, of androgens $(2,5)$. In the salt-wasting type of the disease, hyponatremia, hyperkalemia, and hyperreninemia are also found (2). Finally, analysis of the 21-hydroxylase gene is useful to confirm the defect in affected children and to establish a diagnosis in uncertain cases and can also help in the management of CAH (8, 9, 24-26).

Whereas the clinical management of affected infants is well standardized $(2,9,27-29)$, the management and follow-up of newborns positive at neonatal screening for CAH presenting only slightly increased 17-OHP serum levels have as yet been unknown. In particular, it is debated whether it is necessary to start a therapy for these infants, and whether it has to start from birth with consequent overtreatment in the mildly affected cases (30). Nowadays, this population of infants is often submitted to a difficult and lengthy series of clinical investigations with the resultant psychological stress for their families. Among the newborns who are false positive at screening, only one case of transient hyper17-hydroxyprogesteronemia (hyper-17-OHPemia) has been described to date in a preterm newborn submitted to multiple clinical and biochemical examinations (31).

From 2002 to 2006, we investigated all infants who tested positive at neonatal screening for 21-OHD and were referred to Necker-Enfants Malades Hospital in Paris to evaluate their clinical conditions. Consequently, the aims of this study were:

- to identify clinically, biochemically, and by genotyping a particular population of infants with transient serum hyper-17-OHPemia;

- to compare their clinical features with those of neonates affected by 21-OHD and false-positive ones.

\section{Subjects and methods}

\section{Patients}

We retrospectively analyzed the clinical data of all newborns referred to the Paediatric Endocrinology Department of the Necker-Enfants-Malades Hospital in Paris, Ile de France, over the period 2002-2006 for confirmation of a positive result at $\mathrm{CAH}$ neonatal screening.

In the Ile de France area, suspicion of 21-OHD was based on a $17-\mathrm{OHP}$ value $\geq 50 \mathrm{nmol} / \mathrm{l}$ at screening tests performed using a solid-phase time-resolved fluoroimmunoassay method for 17-OHP determination (AutoDELFIA Neonatal 17-OHP Kit, Wallac Oy, Turku, Finland) between the third and fifth day after birth. For preterm newborns, this threshold value was obtained after a second screening test performed at 36 weeks, corrected for GA, if the first 17-OHP screening value was $>70 \mathrm{nmol} / \mathrm{l}$. Consequently, only preterm babies with a second positive screening test were recalled to a Paediatric Endocrinology Centre for a complete clinical evaluation. GA and BW were calculated on the basis of the data reported on the filter paper of each infant.

\section{Methods}

All newborns were immediately recalled to our department in order to be submitted to the clinical and biochemical investigations needed to confirm the disease. All infants were evaluated to determine their weight, height, and degree of virilization according to the Prader scale (32) and were submitted to blood tests to detect 17-OHP, renin, and electrolyte levels. In addition, serum measurements of androstenedione, testosterone, ACTH, DHEAS, and urinary electrolytes were performed in almost all infants.

According to the normal literature limits for age $(2,33-35)$ adapted to a control population $(n=294)$ of similarly aged French children with the same GA range (32-41 weeks) who were previously referred to our hospital, we considered $<9 \mathrm{nmol} / \mathrm{l}$ as a normal 17-OHP serum value for infants in the first months of life. Consequently, on the basis of 17-OHP levels at the first serum measurement, newborns were classified in three groups: infants affected by $\mathrm{CAH}$, infants with serum 17-OHP levels $<9 \mathrm{nmol} / \mathrm{l}$ (simple false-positive infants), and newborns with serum 17-OHP level higher than $9 \mathrm{nmol} / \mathrm{l}$ without other clinical or biochemical signs of 21-OHD (hyper-17-OHPemia infants).

All affected babies, according to their clinical signs and serum results, started the treatment and were submitted to the genetic study of the 21-hydroxylase gene in order to confirm the diagnosis. Simple false-positive infants were not submitted to any further investigations, whereas hyper-17-OHPemia infants were submitted to strict clinical and biochemical follow-up monitoring until their 17-OHP serum values decreased.

In particular, all infants with serum hyper-17-OHPemia underwent an ACTH-stimulation test (administration of a single i.v. injection of $0.25 \mathrm{mg}$ of ACTH and hormonal measurements at time 0 and $60 \mathrm{~min}$ after administration) in the first months of life. Genetic analysis to detect mutations of the 21-hydroxylase gene was also performed in all these infants, some in the neonatal period, and others later.

\section{Hormone analysis}

Serum 17-OHP (CISBio International, Gif-sur-Yvette, France), $\Delta 4$-androstenedione (Immunotech, Marseille, France), testosterone (Orion Diagnostica, Espoo, Finland), DHEAS (Immunotech), renin (CISBio International), cortisol (CORT-CT2, CIS Bio), and ACTH (CISBio International) were measured by RIA. 17-OHP, testosterone, and $\Delta 4$-androstenedione measurements were performed after an extraction process in an ethyl ether solvent as previously described (36-38). 
Serum 11-deoxycortisol levels were measured using a specific time-resolved fluoroimmunoassay after an extraction plus celite chromatography partition step (39).

\section{Genetic analysis}

The 21-hydroxylase gene was analyzed using DNA isolated from peripheral blood samples with the informed consent of the parents. The molecular study was performed according to a cascade strategy, permitting the exploration of the entire gene at the Endocrine and Molecular Biochemistry Laboratory of Debrousse Hospital, Lyon, France (40).

\section{Statistical analysis}

All statistical analyses were performed using the $\mathrm{R}$ software package. Comparisons between groups were performed using Student's $t$-test or the Wilcoxon rank-sum test, when appropriate. Data are expressed as numbers with frequency, median plus range, or mean \pm s.D., as appropriate. Statistical significance was considered when $P$ values were $<0.05$, and all tests were two-sided.

\section{Results}

\section{Subjects}

Among the 437542 infants screened at Necker screening laboratory between 2002 and 2006, 121 newborns were recalled to a Pediatric Endocrinology Centre for further evaluations and 26 resulted affected by 21-OHD, yielding an incidence of 1:16 800. Over this period, 37 newborns (23 males $(\mathrm{M})$ and 14 females $(\mathrm{F}))$, with GA ranging from 33 to 40 weeks (median: 37 weeks), were referred to our department on average at $11.7 \pm 7.9$ days of life to confirm a positive result at 21-OHD neonatal screening. All of them were submitted to a screening test on average at $3.5 \pm 0.5$ days of life, preterm babies repeated the screening test on average at $12.6 \pm 3.5$ days of life.
Among these 37 newborns, we identified eight infants affected by 21-OHD (21.6\%; three $M$ and five F), 14 simple false-positive infants $(37.8 \%$; ten $\mathrm{M}$ and four $\mathrm{F})$, and 15 hyper-17-OHPemia newborns $(40.6 \%$; ten $\mathrm{M}$ and five $\mathrm{F}$ ).

\section{Neonatal features}

The neonatal features of all newborns, divided by groups, are expressed in Table 1 . We notice a significant difference in GA in the group of newborns with serum hyper-17-OHPemia in comparison with the other groups of infants $(P<0.01)$. Nine infants with the serum hyper-17-OHPemia had a GA ranging from 33 to 35 weeks, whereas all the infants in the other two categories had a GA of over 35 weeks. Whereas statistically significant differences were found in all the other neonatal features of the affected children in comparison with hyper-17-OHPemia infants $(P<0.01)$, only birth length was significantly different between simple false positives and hyper-17-OHPemia infants $(P<0.05)$. Surprisingly, there was no statistical difference in BW between these two groups of newborns. Moreover, whereas all hyper-17-OHPemia newborns had a BW appropriate for GA, one male (BW: $2070 \mathrm{~g}, \mathrm{GA}: 40$ weeks) among the simple false positives was 'small for GA' (BW < third percentile for GA) according to Leroy-Lefort's norms for the French population (41).

\section{Clinical findings}

Clinically, unaffected newborns had no signs of CAH; in particular, they had no virilization of the external genitalia or severe dehydration. Three simple falsepositive newborns presented neonatal jaundice treated by phototherapy and two other infants in this group presented transient neonatal respiratory distress. One female infant in this group was affected by a severe metabolic disease. The other babies $(n=8 ; 57 \%)$ in this group presented no clinical abnormalities. Of the hyper17-OHPemia infants, three, including two twins, with

Table 1 Description of neonatal features of three groups of newborns with positive neonatal screening for congenital adrenal hyperplasia.

\begin{tabular}{|c|c|c|c|}
\hline & \multirow[b]{2}{*}{ Affected newborns } & \multicolumn{2}{|l|}{ Unaffected newborns } \\
\hline & & $\begin{array}{l}\text { Simple false-positive newborns } \\
\text { (serum } 17-\mathrm{OHP}<9 \mathrm{nmol} / \mathrm{l} \text { ) }\end{array}$ & $\begin{array}{l}\text { Hyper-17-OHPemia infants } \\
\text { (serum } 17-\mathrm{OHP}>9 \mathrm{nmol} / \mathrm{l})\end{array}$ \\
\hline Number of newborns (male/female) & $8(3 / 5)$ & $14(10 / 4)$ & $15(10 / 5)$ \\
\hline Birth weight $(\mathrm{g})$ & $\begin{array}{l}3582.5 \pm 501.4^{\dagger} \\
(2650-4250)\end{array}$ & $\begin{array}{l}3006.4 \pm 529.6 \\
(2070-3750)\end{array}$ & $\begin{array}{l}2711.3 \pm 399.9 \\
(2070-3310)\end{array}$ \\
\hline Birth length $(\mathrm{cm})$ & $\begin{array}{l}50.9 \pm 2.3^{\dagger} \\
(47-53)\end{array}$ & $\begin{array}{l}49.1 \pm 1.7^{*} \\
(46.5-52)\end{array}$ & $\begin{array}{l}47.5 \pm 2.2 \\
(46.5-52)\end{array}$ \\
\hline Gestational age (weeks) & $\begin{array}{l}39.3 \pm 1.4^{\dagger} \\
(36-41)\end{array}$ & $\begin{array}{l}37.4 \pm 1.4^{\dagger} \\
(36-40)\end{array}$ & $\begin{array}{l}35.7 \pm 1.8 \\
(33-39)\end{array}$ \\
\hline Time at first investigation (days) & $2(1-13)^{\dagger}$ & $10(7-15)$ & $12(8-38)$ \\
\hline
\end{tabular}

The data are expressed as mean \pm s.D.; values in brackets represent the range. $P$ values correspond to the comparison with hyper-17-OHPemia group. ${ }^{\star} P<0.05,{ }^{\dagger} P<0.01$. 
GA ranging from 34 to 36 weeks, had transient respiratory distress and neonatal jaundice treated by phototherapy, one a suspected neonatal infection treated by antibiotic therapy, one congenital hypothyroidism, one duodenal stenosis treated surgically, and another a urinary malformation submitted to nephrostomy at birth. No clinical alterations were detected in the other infants in this group $(n=8 ; 53 \%)$. Three hyper-17-OHPemia infants had a twin (one monozygotic and two heterozygotic) with negative neonatal screening findings: the siblings were consequently not submitted to clinical investigations.

In four out of five affected girls, the diagnosis was clinically established on the first and second days of life on the basis of severe virilization, three of whom with Prader stage 4 and one with Prader stage 3. The other affected girl was incorrectly assigned as male at birth for the major virilization (Prader stage 4) and the disorder was identified only by positive screening at the eighth day of life; a karyotype finally confirmed the female sex. None of the three boys had clinical signs of the disease and they were identified only by a positive neonatal screening. All affected newborns presented a saltwasting form of 21-OHD of variable clinical seriousness, from moderate to severe, but neonatal screening prevented acute salt loss crisis in all of them. Treatment with hydrocortisone, fludrocortisone, and sodium chloride supplementation was started in all of them at a median age of 5.5 (2-15) days of life.

\section{Biochemical findings}

Significant differences in 17-OHP values were found at screening tests between simple false positives and hyper17-OHPemia infants: median 17-OHP screening values were 57 (51-103) nmol/l for simple false positives and 80 (50-199) nmol/l for hyper-17-OHPemia infants $(P<0.05)$. In affected newborns, the median 17-OHP screening value was $305(80-773) \mathrm{nmol} / \mathrm{l}(P<0.01)$. The distribution of the results of neonatal screening for $\mathrm{CAH}$ in all 37 infants is shown in Fig. 1.

At the first serum evaluation, unaffected infants showed significant differences $(P<0.001)$ in their 17-OHP values: $3.75(0.3-8.4) \mathrm{nmol} / \mathrm{l}$ and 15.9 (9.9-33) nmol/l in the simple false positives and hyper-17-OHPemia infants respectively. Affected newborns presented a median serum 17-OHP value of $277.5(210-921) \mathrm{nmol} / \mathrm{l}$.

We identified a slight elevation in androgen levels in the hyper-17-OHPemia infants in comparison to the literature reference levels for age (42). Obviously, all androgen levels were abnormally increased in affected newborns, whereas they were in the normal range in simple false positives. No significant differences were found in the plasma renin values of unaffected newborns: median $56.5(8-186) \mathrm{pg} / \mathrm{ml}$ and 46 (20-112) $\mathrm{pg} / \mathrm{ml}$ for simple false positives and hyper-170HPemia infants respectively. ACTH and serum and urinary

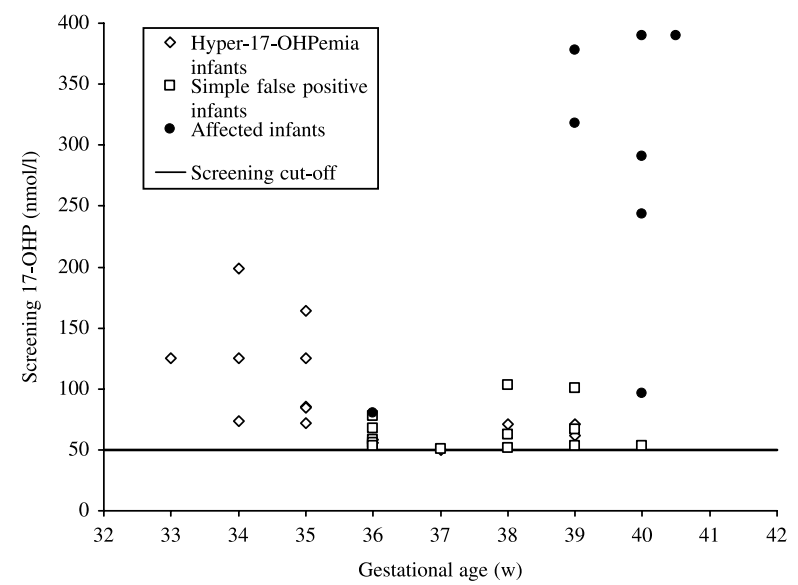

Figure 1 Blood spot 17-OHP levels in the screening of three groups of newborns in relation to gestational age. For affected newborns, $400 \mathrm{nmol} / \mathrm{l}$ are used as the maximum value in this representation.

electrolyte values were normal for newborns in these two groups. On the contrary, affected newborns presented the differences in electrolyte values in relation to the day of clinical diagnosis of the disease; newborns with an early diagnosis had normal $\mathrm{Na}$ and $\mathrm{K}$ serum levels in comparison with the infants with a later diagnosis who presented slight hyponatremia and hyperkalemia. Moreover, plasma renin levels changed according to the day the diagnosis was made: they were normal in girls with an early diagnosis and a little elevated in the others. Urinary electrolyte values showed inappropriately increased sodium levels in infants with a later diagnosis and normal values in the others. All these data are taken before a treatment was started.

All hyper-17-OHPemia infants were submitted to an ACTH-stimulation test at a median age of 37 (13-190) days of life (Table 2). The majority (93.3\%) presented abnormal 17-OHP values in relation to the normal reference values in the literature $(40,43,44)$; moreover, if we plot these results on New's nomogram (45) 13 infants $(86.7 \%)$ were in the range of heterozygotes, 1 in the range of patients with a non-classic form of $\mathrm{CAH}$, and 1 in the range of unaffected infants. This normal result was found for a girl who was submitted to the

Table 2 Results of ACTH-stimulation test in hyper-17-hydroxyprogesteronemia infants expressed as mean \pm s.D.

\begin{tabular}{lll}
\hline & Basal values & Stimulated values \\
\hline $\begin{array}{lll}17-\mathrm{OHP}(\mathrm{nmol} / \mathrm{l}) \\
\text { Cortisol }(\mu \mathrm{g} / \mathrm{dl})\end{array}$ & $11.4 \pm 6.3(1.1-26.1)$ & $18.6 \pm 8.1(9.9-30.9)$ \\
$\begin{array}{l}\Delta 4-\text { Androstenedione } \\
(\mathrm{ng} / \mathrm{ml})\end{array}$ & $1.8 \pm 1.6(0.2-5.0)$ & $2.7 \pm 2.2(0.5-7.4)$ \\
$\begin{array}{l}11-\mathrm{Deoxycortisol} \\
(\mathrm{ng} / \mathrm{ml})\end{array}$ & $1.3 \pm 1.1(0.1-3.5)$ & $1.8 \pm 1.2(0.5-4.0)$ \\
\hline
\end{tabular}

Values in the brackets represent the range. 
stimulation test only at 6 months of life because at the first month of life she was suffering from a pulmonary infection and at that time the parents refused to submit their daughter immediately to an ACTH-stimulation test.

\section{Genotyping}

The 21-hydroxylase gene was analyzed in all affected newborns and in all hyper-17-OHPemia infants. Whereas all newborns in the former group presented mutations related to the classic salt-wasting form of 21-OHD, no mutations of this gene were found in any infants in the latter group. All infants affected by $\mathrm{CAH}$ evidenced a good genotype-phenotype correlation.

\section{Evolution}

17-OHP serum levels of all hyper-17-OHPemia infants were reduced between the third and the sixth month of life independently by GA (Fig. 2). Statistical evaluation of the time trends of other serum androgen levels was impossible in children of this group because they were not measured in all of them at the same time. Nevertheless, we noticed a progressive reduction in androstenedione, testosterone, and DHEAS serum levels with time to the point of complete normalization (Table 3). Renin, ACTH (Table 3), and electrolyte serum levels remained normal also in subsequent measurements. The clinical follow-up findings in these infants were completely normal in comparison with other babies of the same age, and, in particular, their growth was regular and no signs of virilization were detected.

\section{Discussion}

This study analyses the clinical management of positive newborns at CAH screening and allows us to describe a population of infants with transient serum hyper17-OHPemia. We found, in fact, that $40.6 \%$ of all positives at neonatal screening for $21-\mathrm{OHD}$ referred to our department had a slight elevation of 17-OHP serum

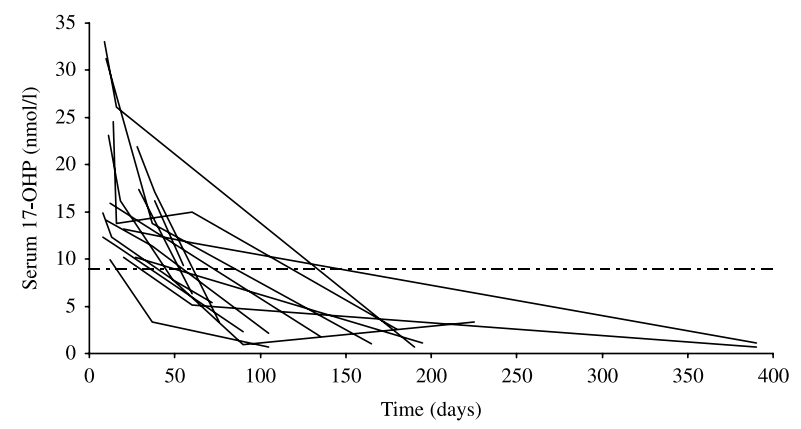

Figure 2 Time trend of serum 17-OHP values in hyper17-OHPemia infants. values that was normalized only by the third month of life. All these children had no clinical signs of 21-OHD or 21-hydroxylase gene mutations. This is an interesting finding especially because, to the best of our knowledge, it is the first time that a population of false positives at 21-OHD screening has been specifically described in the literature. Although this is a retrospective study and presents the typical limitations of this kind of investigation, we believe that it may be useful in the management of newborns with transient serum hyper-17-OHPemia.

It is well known that increased 17-OHP levels are common in preterm and low BW infants (13-15, 35), and are especially premature newborns with a GA of $<31$ weeks to have elevated screening 17-OHP levels without inborn errors of steroid biosynthesis (46), also in relation to the physiologically delayed expression of the enzyme 11- $\beta$-hydroxylase (47). On the contrary, all newborns of our population had a GA of at least 33 weeks and presented normal values of 11-deoxycortisol before and after ACTH stimulation. Moreover, the Ile de France screening strategy is characterized by a second screening test performed after 36 weeks, corrected for $\mathrm{GA}$, in all premature newborns with an increased 17-OHP at the first screening evaluation. Consequently, the preterm infants described in this paper showed an increased 17-OHP value at screening investigation performed when they achieved the correct age of at least 36 weeks, so we might affirm that their increased 17-OHP levels were independent from GA. However, the high percentage of preterm newborns in the group of hyper-17-OHPemia infants in comparison with simple false-positive infants suggests that GA is involved in this finding, although no direct correlation between GA and the 17-OHP serum levels was found in our evaluation. Finally, among the hyper-17-OHPemia infants there were also term babies and none of them was small for GA according to Leroy-Lefort's norms (41). Therefore, premature birth or low BW are not the only factors responsible for transient hyper-17-OHPemia. This is in contrast with the previous literature where the only report characterized by transient hyper-17-OHPemia was in a preterm male born at 35 weeks GA (31).

We may suppose that other factors may contribute to transient hyper-17-OHPemia, such as neonatal jaundice or neonatal disease, which was present in seven newborns in this category. In fact, hyperbilirubinemia may contribute to higher 17-OHP values due to the effect of dehydration on blood concentration (24), and neonatal stress may increase ACTH and 17-OHP levels (19). However, six simple false-positive neonates presented the same neonatal pathologies without any elevation of serum 17-OHP levels.

Two siblings both belonged to the group of hyper17-OHPemia infants and another three newborns in this group had a twin (one homozygote) with a normal screening test and a BW below that of their twins in two out of three cases. This might be another stressful factor 
Table 3 Time trends of serum androgen and renin levels in hyper-17-hydroxyprogesteronemia infants.

\begin{tabular}{llll}
\hline & $\begin{array}{l}\text { First measurement } \\
(17.1 \pm 9.4 \mathrm{~d})\end{array}$ & $\begin{array}{l}\text { Second measurement } \\
(47.0 \pm 46.2 \mathrm{~d})\end{array}$ & $\begin{array}{l}\text { Third measurement } \\
(111.2 \pm 45.4 \mathrm{~d})\end{array}$ \\
\hline 44-Androstenedione $(\mathrm{ng} / \mathrm{ml})$ & $1.9(0.4-6.7)$ & $1.3(0.2-5.0)$ & $0.5(0.2-0.7)$ \\
& $(n=9)$ & $(n=12)$ & $\begin{array}{l}(n=12) \\
0.3(0.1-1.8) \\
(n=12)\end{array}$ \\
Testosterone $(\mathrm{ng} / \mathrm{ml})$ & $0.5(0.2-2.2)$ & $0.6(0.1-2.5)$ & $276.0(101.0-977.0)$ \\
& $(n=7)$ & $1265.0(174.0-1837.0)$ & $(n=10)$ \\
DHEAS $(\mathrm{pg} / \mathrm{ml})$ & $1544.0(551.0-2774.0)$ & $(n=11)$ & $39.1(9.6-120.0)$ \\
Renin $(\mathrm{pg} / \mathrm{ml})$ & $(n=5)$ & $38.0(19.0-121.0)$ & $(n=10)$ \\
ACTH $(\mathrm{pg} / \mathrm{ml})$ & $46.0(20.0-111.8)$ & $4=13)$ & $73.5(7.4-181.3)$ \\
& $(n=10)$ & $(n=13)$ & $(n=6)$ \\
\hline
\end{tabular}

The data are represented as median plus range. $\mathrm{d}$, days.

related to the elevated 17-OHP level, but it is hard to explain why the siblings did not present a similar increase in 17-OHP.

Increased 17-OHP levels might be related to crossreactions of 17-OHP with conjugated steroid metabolites (48), even if 17-OHP measurement was performed after an extraction process used in order to minimize these reactions. Extraction reduces in fact the levels of interfering metabolites in the sample, increasing the specificity of the serum 17-OHP analysis but it does not completely eliminate these reactions. On the other hand, the same analytic procedure for 17-OHP serum determination was performed for all infants analyzed, consequently the same percentage of cross reactions might be present also in simple false-positive infants who nevertheless showed normal 17-OHP serum values.

Whereas rarer enzymatic deficits of adrenal biosynthesis are excluded in all hyper-17-OHPemia infants according to the results of the ACTH-stimulating test, we may hypothesize that a low 21-OH enzymatic function was associated with this clinical condition, according to the explanations suggested by Mizuno et al. (31). Moreover, we believe that this enzymatic immaturity may also be present in some term babies and that post-birth adrenal maturation may be slower than maturation during fetal life, since the persistent elevation of 17-OHP levels. However, this reduced function of 21-OH enzyme does not seem to compromise the adrenocortical function, as shown by their normal cortisol values after ACTH-stimulation test and by the adequate adaptation to stressful conditions as surgical intervention in the absence of cortisol supplementation.

No mutations were found in any of hyper17-OHPemia infants, even when presenting heterozygote status according to New's nomogram, after ACTH-stimulation (45). On the contrary, all infants affected by CAH showed a panel of mutations related to a classic form of 21-OHD with salt loss, according to their phenotype. This result further confirms the good genotype-phenotype correlation present in 21-OHD, as previously described in literature $(25,49,50)$. Molecular genetic analysis is not essential for the diagnosis, but is useful to confirm and for the management of the
CAH (8, 9). It appears as an ideal diagnostic complement providing prognostic information on the degree of disease severity as well as on the discrimination against false-positive cases (30). Nevertheless, it is essential to submit an infant to genotype analysis when there is a high suspicion of the disease (28); consequently, we believe that 21-hydroxylase gene analysis, in newborns with only slightly increased 17-OHP serum levels, is an advanced tool that might be performed preferably in the late childhood if clinical signs are present.

Neonatal screening for 21-OHD is not designed to detect non-classical $\mathrm{CAH}$ also because basal serum 17-OHP levels are often in the normal range in patients with this form of the disease; nevertheless, it is possible that screening programs and serum confirmation tests permit the early diagnosis of this form of 21-OHD $(8,9$, 23). At the moment, it is not recommended to treat infants affected by non-classical form of 21-OHD until symptoms and signs of androgens excess become evident, but an annual follow-up by a pediatric endocrinologist to check growth rate and signs of the disease is suggested $(2,23,27,28)$. Consequently, the central question in the management of infants with positive neonatal screening consists in the necessity to submit asymptomatic newborns with only slight 17-OHP levels to complete exams to exclude middle form of 21-OHD, which in neonatal period may not require any treatment but only of adequate follow-up during the time. At the end of a long clinical, biochemical, and genotyping follow-up, very stressful for infants and their parents, we can affirm that all of them presented a transient and uncomplicated serum hyper-17-OHPemia that did not need to treatment. Consequently, it is imperative to avoid further investigations if the 17-OHP levels decrease within the first months of life and to reassure the parents about the conditions of their neonates as soon as possible.

In conclusion, we confirmed the benefits of neonatal screening for newborns affected by the classic form of 21-OHD, particularly for males and for females with major virilization of the external genitalia, initially identified as males. Moreover, among the false positives 
at 21-OHD screening, we described a population of infants with transient serum hyper-17-OHPemia, no clinical signs of disease and no 21-hydroxylase gene mutations. The biochemical values of all these infants were normalized within the sixth month of life. We suggest that no further investigations are necessary after birth in these newborns if their 17-OHP levels decrease, and that other confirmatory test as ACTHstimulation test or genotyping analysis is necessary only if symptoms appear.

\section{Declaration of interest}

The authors declare that there is no conflict of interest that could be perceived as prejudicing the impartiality of the research reported.

\section{Funding}

This research did not receive any specific grant from any funding agency in the public, commercial, or not-for-profit sector.

\section{Acknowledgements}

We thank Valerie Gauthereau and Professor Paul Czernichow of French Association for the Diagnosis and Prevention of Child Handicap (AFDPHE) for their contribution to this project; Patricia Dion and Marie-Claire Castellotti of the Neonatal Screening Laboratory of Necker-Enfants Malades Hospital for their valuable help in this work; Dr Christine Trivin of Physiology Laboratory of Necker-EnfantsMalades Hospital for help in the collection of the data; Professor Philippe Boudou of Saint-Louis Hospital of Paris for the measurement of 11-deoxycortisol, Drs Zeina Ajaltouni, Caroline Thalassinos, and Graziella Pinto of the Paediatric Endocrinology Department of NeckerEnfants-Malades Hospital for their cooperation in the follow up of the patients. Authors are also grateful to Professor Luciano Tatò of Pediatric Department of University of Verona, Verona, Italy.

\section{References}

1 Hughes IA. Congenital adrenal hyperplasia - a continuum of disorders. Lancet $1998352752-754$.

2 Speiser PW \& White PC. Congenital adrenal hyperplasia. New England Journal of Medicine $2003 \mathbf{3 4 9}$ 776-788.

3 New MI \& Wilson RC. Steroid disorders in children: congenital adrenal hyperplasia and apparent mineralocorticoid excess. PNAS 199996 12790-12797.

4 Riepe FG \& Sippell WG. Recent advances in diagnosis, treatment, and outcome of congenital adrenal hyperplasia due to 21-hydroxylase deficiency. Reviews in Endocrine and Metabolic Disorders 20078 349-363.

5 Speiser PW. Congenital adrenal hyperplasia owing to 21-hydroxylase deficiency. Endocrinology and Metabolism Clinics of North America $20013031-59$.

6 New MI. Nonclassical 21-hydroxylase deficiency. Journal of Clinical Endocrinology and Metabolism 200691 4205-4214.

7 Morel Y \& Miller WL. Clinical and molecular genetics of congenital adrenal hyperplasia due to 21-hydroxylase deficiency. Advances in Human Genetics 199120 1-68.

8 Joint ESPE/LWPES CAH Working Group. Consensus statement on 21-hydroxylase deficiency from the European Society for Paediatric Endocrinology and Lawson Wilkins Pediatric Endocrine Society. Hormone Research 200258 188-195.

9 Joint ESPE/LWPES CAH Working Group. Consensus statement on 21-hydroxylase deficiency from the Lawson Wilkins Pediatric
Endocrine Society and the European Society for Paediatric Endocrinology. Journal of Clinical Endocrinology and Metabolism $2002874048-4053$.

10 Therrell BL. Newborn screening for congenital adrenal hyperplasia. Endocrinology and Metabolism Clinics of North America 200130 15-30.

11 American Academy of Pediatrics. Section on Endocrinology and Committee on Genetics. Techical report: congenital adrenal hyperplasia. Pediatrics 2000106 1511-1518.

12 Dhondt JL, Dorche C, Farraiux JP \& Courte C. Neonatal screening for congenital adrenal hyperplasia: a pilot study in France. Journal of Inherited Metabolic Disease 19869 147-151.

13 Torresani T, Grüters A \& Acherz R. Improving the efficacy of newborn screening for congenital adrenal hyperplasia by adjusting the cut-off level of 17- $\alpha$-hydroxyprogesterone to gestational age. Screening $1994377-84$.

14 Honour JW \& Torresani T. Evaluation of neonatal screening for congenital adrenal hyperplasia. Hormone Research 200155 206-211.

15 Berry J, Betts P \& Wood PJ. The interpretation of blood spot $17 \alpha$-hydroxyprogesterone levels in term and pre-term neonates. Annals of Clinical Biochemistry 198623 546-551.

16 Van Der Kamp HJ, Oudshoorn CGM, Elvers BH, Van Baarle M, Otten BJ, Wit JM \& Verkerk PH. Cut-off level of 17- $\alpha-$ hydroxyprogesterone in neonatal screening for congenital adrenal hyperplasia should be based on gestational age rather than on birth weight. Journal of Clinical Endocrinology and Metabolism 2005 90 3904-3907.

17 Cavarzere P, Camilot M, Teofoli F \& Tatò L. Neonatal screening for congenital adrenal hyperplasia in North-Eastern Italy: a report three years into the program. Hormone Research 200563 180-186.

18 Nordenström A, Wedell A, Hagenfeldt L, Marcus C \& Larsson A. Neonatal screening for congenital adrenal hyperplasia: 17-hydroxyprogesterone levels and CYP21 genotypes in preterm infants. Pediatrics $2001 \mathbf{1 0 8}$ e68.

19 Gruñeiro-Papendieck L, Prieto L, Chiesa A, Bengolea S, Bossi G \& Bergadá C. Neonatal screening program for congenital adrenal hyperplasia: adjustments to the recall protocol. Hormone Research 200155 271-277.

20 Steigert M, Schoenle EJ, Biason-Lauber A \& Torresani T. High reliability of neonatal screening for congenital adrenal hyperplasia in Switzerland. Journal of Clinical Endocrinology and Metabolism $2002874106-4110$.

21 Allen DB, Hoffman GL, Fitzpatrick P, Laessing R, Maby S \& Slyper A. Improved precision of newborn screening for congenital adrenal hyperplasia using weight-adjusted criteria for 17-hydroxyprogesterone levels. Journal of Pediatrics 1997130 128-133.

22 Olgemöller B, Roscher AA, Liebl B \& Fingerhut R. Screening for congenital adrenal hyperplasia: adjustment of 17-hydroxyprogesterone cut-off values to both age and birth weight markedly improves the predictive value. Journal of Clinical Endocrinology and Metabolism $2003 \mathbf{8 8}$ 5790-5794.

23 Working Group on Neonatal Screening of the European Society for Paediatric Endocrinology. Procedure for neonatal screening for congenital adrenal hyperplasia due to 21-hydroxylase deficiency. Hormone Research 200155 201-205.

24 Root AW. Editorial: neonatal screening for 21-hydroxylase deficient congenital adrenal hyperplasia-the role of CYP21 analysis. Journal of Clinical Endocrinology and Metabolism 1999 84 1503-1504.

25 Forest MG, Tardy V, Nicolino M, David M \& Morel Y. 21-Hydroxylase deficiency: an exemplary model of the contribution of the molecular biology in the understanding and management of the disease. Annales d'Endocrinologie 200566 225-232.

26 Pinto G, Tardy V, Trivin C, Thalassinos C, Lortat-Jacob S, Nihoul-Fèkètè C, Morel Y \& Brauner R. Follow up of 68 children with congenital adrenal hyperplasia due to 21-hydroxylase deficiency: relevance of genotype for management. Journal of Clinical Endocrinology and Metabolism 200388 2624-2633.

27 Merke DP \& Bornstein SR. Congenital adrenal hyperplasia. Lancet $20053652125-2136$. 
28 White PC \& Speiser PW. Congenital adrenal hyperplasia due to 21-hydroxylase deficiency. Endocrine Reviews 200021 245-291.

29 Bachelot A, Plu-Bureau G, Thibaud E, Laborde K, Pinto G, Samara D, Nihoul-Fékété C, Kuttenn F, Polak M \& Touraine P. Long-term outcome of patients with congenital adrenal hyperplasia due to 21-hydroxylase deficiency. Hormone Research 200767 268-276.

30 Nordenström A, Thilén A, Hagenfeldt L, Larsson A \& Wedell A. Genotyping is a valuable diagnostic complement to neonatal screening for congenital adrenal hyperplasia due to steroid 21-hydroxylase deficiency. Journal of Clinical Endocrinology and Metabolism 199984 1505-1509.

31 Mizuno H, Ohro Y, Sugiyama Y, Ito T, Hasegawa T, Homma K, Ueshiba H, Ono M \& Togari H. Transient hyper-17-OHPnemia unrelated to cross-reactions with residual fetal adrenal cortex products. Hormone Research $200461242-245$.

32 Prader A. Der Genitalbefund beim Pseudohermaphroditismus femininus der kongenitalen adrenogenitalen syndroms. Helvetica Paediatrica Acta $19549231-248$.

33 Godò B, Visser HKA \& Degenhart HJ. Plasma 17-OH-progesterone in fullterm and pre-term infants at birth and during early neonatal period. Hormone Research 198115 65-71.

34 Lashansky G, Saenger P, Fishman K, Gautier T, Mayes D, Berg G, Di Martino-Nardi J \& Reiter E. Normative data for adrenal steroidogenesis in a healthy pediatric population: age- and sexrelated changes after adrenocorticotropin stimulation. Journal of Clinical Endocrinology and Metabolism 199173 674-686.

35 Lee MM, Rajagopalan L, Berg GJ \& Moshang T Jr. Serum adrenal steroid concentrations in premature infants. Journal of Clinical Endocrinology and Metabolism 198969 1133-1136.

36 Forest MG. Use of highly specific antibodies against $17 \alpha-\mathrm{OH}$ progesterone in a simplified non chromatographic RIA and in the simultaneous determination of sex hormones in human plasma. Hormone Research 19767 260-273.

37 Forest MG, Cathiard AM \& Bertrand J. Total and unbound testosterone levels in the newborn and in normal and hypogonadal children: use of a sensitive radioimmunoassay for testosterone. Journal of Clinical Endocrinology and Metabolism 197336 1132-1142.

38 Forest MG. Plasma androgens (testosterone and 4-androstenedione) and 17-hydroxyprogesterone in the neonatal, prepubertal and peripubertal periods in the human and the rat: differences between species. Journal of Steroid Biochemistry 197911 543-548.

39 Fiet J, Giton F, Boudou P, Villette JM, Soliman H, Morineau G, Boudi A \& Galons H. A new specific and sensitive time resolvedfluoroimmunoassay of 11-deoxycortisol in serum. Journal of Steroid Biochemistry and Molecular Biology 200177 143-150.

40 Menassa R, Tardy V, Despert F, Bouvattier-Morel C, Brossier JP, Cartigny M \& Morel Y. p.H62L, a rare mutation of the CYP21 gene identified in two forms of 21-hydroxylase deficiency. Journal of Clinical Endocrinology and Metabolism 200893 1901-1908.
41 Leroy B \& Lefort F. The weight and size of newborn infants at birth. Revue Française de Gynécologie et d'Obstétrique 197166 391-396.

42 Forest MG, De Peretti E \& Bertrand J. Testicular and adrenal androgens and their binding to plasma proteins in the perinatal period: developmental patterns of plasma testosterone, 4-androstenedione, dehydroepiandrosterone and its sulphate in premature and small for date infants as compared with that of fullterm infants. Journal of Steroid Biochemistry 198012 25-36.

43 Pham-Huu-Trung MT, Gourmelen M, Raux-Eurin MC \& Girard F. Pituitary-adrenal axis activity in treated congenital adrenal hyperplasia: static and dynamic studies. Journal of Clinical Endocrinology and Metabolism 1978 47 422-427.

44 Deneux C, Tardy V, Dib A, Mornet E, Billaud L, Charron D, Morel Y \& Kuttenn F. Phenotype-genotype correlation in 56 women with nonclassical congenital adrenal hyperplasia due to 21-hydroxylase deficiency. Journal of Clinical Endocrinology and Metabolism $200186207-213$.

45 New MI, Lorenzen F, Lerner AJ, Kohn B, Oberfield SE, Pollack MS, Dupont B, Stoner E, Levy DJ, Pang S \& Levine LS. Genotyping steroid 21-hydroxylase deficiency: hormonal reference data. Journal of Clinical Endocrinology and Metabolism $1983 \mathbf{5 7}$ 320-326.

46 Ohkubo S, Shimozawa K, Matsumoto M \& Kitagawa T. Analysis of blood spot 17-alpha-hydroxyprogesterone concentration in premature infants: proposal for cut-off limits in screening for congenital adrenal hyperplasia. Acta Paediatrica Japonica 1992 34 126-133.

47 Hingre RV, Gross SJ, Hingre KS, Mayes DM \& Richman RA. Adrenal steroidogenesis in very low birth weight preterm infants. Journal of Clinical Endocrinology and Metabolism $1994 \mathbf{7 8}$ $266-270$.

48 Lee A \& Ellis G. Serum $17 \alpha$-hydroxyprogesterone in infants and children as measured by a direct radioimmunoassay kit. Clinical Biochemistry 199124 505-511.

49 Wedell A, Thilén A, Ritzén EM, Stengler B \& Luthman H. Mutational spectrum of the steroid 21-hydroxylase gene in Sweden: implications for genetic diagnosis and association with disease manifestation. Journal of Clinical Endocrinology and Metabolism 199478 1145-1152.

50 Dolzan V, Solyum Y, Fekete G, Kovacs J, Rakosnikova V, Votava F, Lebl J, Pribilincova Z, Baumgartner-Parzer SM, Riedl S, Waldhauser F, Frisch H, Stopar-Obreza M, Krzisnik C \& Battelino T. Mutational spectrum of steroid 21-hydroxylase and the genotype-phenotype association in Middle European patients with congenital adrenal hyperplasia. European Journal of Endocrinology 2005 153 99-106.

Received 26 April 2009

Accepted 12 May 2009 